\title{
Evaluation of selective dry cow treatment following on-farm culture: Milk yield and somatic cell count in the subsequent lactation
}

\author{
M. Cameron, ${ }^{* 1}$ G. P. Keefe, ${ }^{*}$ J.-P. Roy, $\dagger$ H. Stryhn, ${ }^{*}$ I. R. Dohoo, ${ }^{*}$ and S. L. McKenna* \\ *Department of Health Management, Atlantic Veterinary College, University of Prince Edward Island, Charlottetown, Prince Edward Island, \\ Canada C1A 4P3 \\ †Faculté de médecine vétérinaire, Université de Montréal, Saint-Hyacinthe, Québec, Canada J2S 7C6
}

\section{ABSTRACT}

Compared with blanket dry cow therapy (DCT), the selective antimicrobial treatment of cows based upon on-farm culture results has the potential to reduce the amount of antimicrobials used in dairy production. The objective of the current study was to determine the effect of a Petrifilm (3M Canada, London, Ontario) on-farm culture-based selective DCT program on milk yield and somatic cell count (SCC) in the following lactation. A total of 729 low-SCC $(<200,000$ cells $/ \mathrm{mL})$ cows from 16 commercial dairy herds with a low bulk tank SCC $(<250,000$ cells $/ \mathrm{mL})$ were randomly assigned to receive either blanket DCT or Petrifilm-based selective DCT. Cows belonging to the blanket DCT group were infused with a commercial DCT product and an internal teat sealant (ITS) at drying off. Using composite milk samples collected on the day before drying off, cows in the selective DCT group were treated at drying off based on the results obtained by the Petrifilm on-farm culture system with DCT and ITS (Petrifilm culture positive) or ITS alone (Petrifilm culture negative). Milk test-day records for the following lactation were obtained from Dairy Herd Improvement for all cows enrolled in the trial. Repeated measures linear mixed models were used to assess the effect of study group (blanket or selective DCT) on test-day milk production and natural logarithm of SCC over the first 180 $\mathrm{d}$ of the subsequent lactation. According to the final multivariable models, when low-SCC cows were selectively treated with DCT at drying off based on results obtained using the Petrifilm on-farm culture system, no effect on milk production (least squares means for blanket DCT $=39.3 \mathrm{~kg}$ vs. selective DCT $=39.0 \mathrm{~kg}$ ) or natural logarithm of SCC (least squares means for blanket DCT $=3.95$ vs. selective $\mathrm{DCT}=3.97)$ was observed in the subsequent lactation when compared with cows receiving blanket DCT. The results of this study

Received September 22, 2014

Accepted December 12, 2014.

${ }^{1}$ Corresponding author: mcameron@upei.ca indicate that selective DCT based on results obtained by the Petrifilm on-farm culture system enabled a reduction in the use of DCT without negatively affecting milk production and milk quality.

Key words: selective dry cow therapy, culture, Petrifilm, somatic cell count, milk yield

\section{INTRODUCTION}

\section{The Economic Importance of Mastitis on Dairy Farms}

Mastitis is a production-limiting and economically important disease of dairy cows (Seegers et al., 2003; Hand et al., 2012). Beyond the direct costs associated with the treatment of mastitis, financial ramifications exist due to decreased milk production and the potential to incur penalties because of poor milk quality. According to an analysis of DHI test-day production records from 2,835 Ontario dairy herds, in comparison to a referent SCC value of $\leq 100,000$ cells $/ \mathrm{mL}$, estimates for 24-h milk production losses at a cow-level SCC of 200,000 cells/mL ranged from 0.35 to $1.09 \mathrm{~kg}$ depending on parity and production levels; at an SCC of 2,000,000 cells $/ \mathrm{mL}$, production losses ranged from 1.49 to $4.7 \mathrm{~kg}$ (Hand et al., 2012). The SCC at the level of the bulk tank is an important indicator of the quality of milk produced at the farm. Consequently, bulk tank somatic cell counts (BTSCC) that exceed regulatory limits can result in financial penalties and the suspension of the right to market milk. Thus, management of both clinical and subclinical mastitis on a dairy farm is very important for the profitability of the farming enterprise.

\section{Mastitis Control over the Dry Period}

With regard to mastitis control, the dry period is considered a critical component of the milk production cycle on the basis of 2 main factors: (1) for existing IMI, high cure rates can be achieved, and (2) the rate of new IMI is greater in the periparturient period 
than at any point during lactation (Smith et al., 1985; Dingwell et al., 2003; Halasa et al., 2009). In North America, blanket dry cow therapy (BDCT) is the most common approach to mastitis control during the dry period (USDA, 2008; Dufour et al., 2012). When using BDCT, all quarters of all cows are infused with a longacting intramammary antimicrobial [dry cow therapy (DCT)] at the end of lactation. As concerns regarding the emergence of antimicrobial-resistant pathogens are on the rise, dairy producers are facing increasing pressure to reduce antimicrobial usage on their farms. For dairy herds with a low prevalence of contagious mastitis and a consistently low BTSCC, an alternative approach to mastitis control over the dry period would be to target antimicrobial treatment at cows with an IMI at drying off, a protocol known as selective dry cow therapy (SDCT). With the advent of internal teat sealants (ITS), producers have at their disposal a nonantimicrobial product that has proven to be just as efficacious as DCT in the prevention of IMI during the nonlactating period (Woolford et al., 1998; Sanford et al., 2006). The addition of an ITS to an SDCT program ensures that all quarters have some form of protection against dry period IMI.

\section{Petrifilm-Based SDCT plus ITS}

In North America, estimates for compliance with a BDCT protocol range from $72 \%$ of herds in the United States to $88 \%$ of herds in Canada (USDA, 2008; Dufour et al., 2012). In order for dairy producers to consider SDCT, the outcomes of the subsequent lactation regarding udder health, milk production, and milk quality must be equivalent to those achieved by BDCT. The majority of studies evaluating SDCT and ITS have focused on the risk of IMI and clinical mastitis in the subsequent lactation, whereas published reports examining the effects on milk yield and SCC are sparse. A consistent theme in SDCT research is that the success of such a program depends on the ability to determine a cow's IMI status at the end of lactation so that the appropriate treatment can be applied (Huxley et al., 2002; Robert et al., 2008; Torres et al., 2008). A Petrifilm (3M Canada, London, Ontario)-based on-farm culture system has recently been validated for use in a SDCT program. When used in low-BTSCC herds $(<250,000$ cells $/ \mathrm{mL})$ to diagnose IMI in cows with a low SCC $(<200,000$ cells $/ \mathrm{mL})$ before drying off, the culture system performed well, with a sensitivity of $85 \%$ and specificity of $73 \%$ (Cameron et al., 2013). Furthermore, Petrifilm-based SDCT did not affect the risk of IMI at calving or the risk of a first case of clinical mastitis in the first $120 \mathrm{~d}$ of lactation when compared with BDCT (Cameron et al., 2014). The aim of the research outlined in the current paper was to evaluate the milk quality and production outcomes in the subsequent lactation following Petrifilm-based SDCT. The main objectives were to compare milk production and SCC in the first $180 \mathrm{~d}$ of lactation between cows receiving BDCT with the addition of an ITS and cows selectively treated based on the results of the Petrifilm on-farm culture system with DCT and an ITS or with an ITS alone.

\section{MATERIALS AND METHODS}

\section{Trial Design}

Cows in a convenience sample of dairy herds from Quebec $(\mathrm{n}=6)$ and Prince Edward Island $(\mathrm{n}=10)$ that entered the dry period between July 2009 and September 2010 were considered for inclusion in the trial. Herd inclusion criteria included an average BTSCC below 250,000 cells $/ \mathrm{mL}$ over the last $12 \mathrm{mo}$ and participation in a DHI program with regular milk testing. Herd size ranged from 44 to 251 cows with a median of 75 cows; the total number of cows entering the dry period during the study period was 1,584. Enrolled cows had monthly SCC $<200,000$ cells $/ \mathrm{mL}$ on the last 3 tests before drying off, no clinical mastitis in the same time period, an expected dry period of 30 to $90 \mathrm{~d}$, no antimicrobial treatment in the last $14 \mathrm{~d}$, at least 3 functional quarters, and all quarters scoring $<2$ on the California mastitis test (scale: negative, trace, 1, 2, 3; Roy et al., 2009) on the day before drying off.

Single quarter milk samples were collected on the day before drying off, at 3 to $4 \mathrm{~d}$ postcalving, and again at 5 to $18 \mathrm{~d}$ postcalving. The first postcalving sample was collected by the producer or farm personnel; all other samples were collected by the study personnel. Milk samples were frozen at $-20^{\circ} \mathrm{C}$ before shipment to the Maritime Quality Milk research laboratory at the University of Prince Edward Island. Following pre-drying off sample collection, cows were randomly assigned to either the blanket dry cow therapy (BDCT+ITS) study group or the Petrifilm-based selective dry cow therapy (SDCT+ITS) study group according to a randomization table unique to each herd with a block size of 6 , thus randomizing 6 cows at a time with 3 to BDCT+ITS and 3 to SDCT+ITS. On the day of drying off, cows in the BDCT+ITS group were infused with a long-acting intramammary formulation of 500 mg of ceftiofur hydrochloride (Spectramast DC, Zoetis Canada, Kirkland, Quebec, Canada) followed by an ITS composed of $65 \%$ bismuth subnitrate (Orbeseal, Zoetis Canada) in all 4 quarters. For cows assigned to the SDCT+ITS group, a composite milk sample was cultured on-farm using the Petrifilm on-farm culture 
system. The Petrifilm on-farm culture was set-up by the study personnel on the day before drying off. First, a composite milk sample was created by combining 5 $\mathrm{mL}$ from each quarter sample into a new sample vial. A 3-mL aliquot of composite milk was then added to $27 \mathrm{~mL}$ of sterile water to make a 1:10 dilution. One milliliter of diluted milk was plated on a total aerobic count Petrifilm and incubated on-farm at $35^{\circ} \mathrm{C}$ for 24 $\mathrm{h}$ in a TurboFan Hova-Bator (GQF Manufacturing, Savannah, GA). Consistent with a dilution factor of 1:10, a single colony-forming unit present on the Petrifilm was equivalent to $10 \mathrm{cfu} / \mathrm{mL}$ of milk. On the scheduled day of drying off (d 0$)$, the Petrifilm was read by the producer and, in accordance with study protocol, cows were classified as positive if 5 or more colonies were present (equivalent to $\geq 50 \mathrm{cfu} / \mathrm{mL}$ of milk). Cows negative on Petrifilm were treated solely with an ITS at drying off; cows positive on Petrifilm were treated with $500 \mathrm{mg}$ of ceftiofur hydrochloride followed by an ITS. All treatments were applied by the producer or farm personnel immediately following the last milking, and treatments were recorded to verify compliance with the study protocol.

\section{Bacteriology}

Within 1 mo from collection, milk samples were thawed and cultured in a laboratory using standardized methods outlined in the Laboratory Handbook on Bovine Mastitis (National Mastitis Council, 1999). Trained laboratory technicians $(\mathrm{n}=2)$ were blinded to the results obtained by the Petrifilm on-farm culture system. Briefly, disposable plastic loops were used to streak $0.01 \mathrm{~mL}$ of milk on bi-plates containing half Columbia agar $+5 \%$ sheep blood and half MacConkey agar. Plates were incubated at $35^{\circ} \mathrm{C}$ and examined for bacterial growth after 24 and $48 \mathrm{~h}$. Colonies were tentatively identified as staphylococci, streptococci, coliforms, or other pathogens based on colony growth characteristics, morphology, pattern of hemolysis, catalase reaction, and Gram staining. Staphylococcal isolates were tested for coagulase production with the tube coagulase test. The API tests (API $20 \mathrm{E}$ and API 20 Strep; bioMérieux, Marcy L'Etoile, France) and the latex agglutination test for streptococcal Lancefield groups were used for the final identification of bacterial organisms as required. For each positive sample, the number of colony-forming units per $0.01 \mathrm{~mL}$ of milk was enumerated up to a maximum of 10 colonies. A quarter was considered infected if $\geq 100 \mathrm{cfu} / \mathrm{mL}$ of milk of any pathogenic organism of interest, except CNS, were cultured. For CNS, a definition of $\geq 200 \mathrm{cfu} / \mathrm{mL}$ was used. Samples with 3 or more differing isolates were classified as contaminated. However, when Staphylococcus aureus was identified in a contaminated sample, it was enumerated and the associated quarter was classified as infected (Reyher et al., 2011). These definitions of IMI are in accordance with the recent publication of characterization of IMI based on single sample bacteriological testing (Dohoo et al., 2011). Organisms classified as other gram-positive, which were mainly Bacillus spp., were assumed to be associated with environmental contamination and considered nonsignificant growth. No samples collected during the trial displayed growth of Streptococcus agalactiae.

The quarter-level culture results were interpreted in parallel to determine the cow-level infection status. If one or more quarter samples were contaminated, a cow was considered infected if at least one of the remaining quarters was infected. If one or more quarter samples were contaminated and no IMI was diagnosed in the remaining samples, the cow's overall infection status was considered unknown, and the observation was removed from the analyses. Throughout this manuscript, infection status or IMI refers to the classification of a cow based on parallel interpretation of quarter-level standard bacteriological culture results, whereas Petrifilm on-farm culture results are referred to simply as Petrifilm positive or Petrifilm negative.

\section{Data Collection}

Data on milk yields and SCC were recorded by DHI technicians on a minimum of 10 separate occasions spaced over the course of 12 mo. Data files were provided by DHI and the following information was extracted for each participating cow: test-day 24 -h milk yield (in $\mathrm{kg}$ ) and SCC during the first $180 \mathrm{~d}$ of lactation (consisting of 5 to 6 milk tests per cow), DIM at the time of the milk test, parity, and the previous lactation 305-d milk production (in $\mathrm{kg}$ ). Additional data collected at the time of collection of postcalving milk samples included the occurrence of postpartum disease (such as metritis, displaced abomasum, or mastitis) and antimicrobial treatment before sample collection.

\section{Statistical Analysis}

Statistical analysis was performed using Stata/IC 11.0 (StataCorp, College Station, TX). Two outcomes of interest were analyzed: test-day 24-h milk production and test-day SCC during the first $180 \mathrm{~d}$ of lactation, and all analyses were at the level of the cow test day. Somatic cell counts (in $1,000 / \mathrm{mL}$ ) were modeled using the natural logarithm of SCC (InSCC). The data consisted of repeated measurements (up to 6 milk tests) within a study subject; therefore, milk yield and lnSCC were modeled using a repeated measures linear mixed 
model. Different correlation structures were assessed (first-order autoregressive, first-order moving average, unstructured, Toeplitz, and exponential), and the most appropriate structure was determined by likelihood ratio tests and Akaike's Information Criteria. For both outcomes, an unstructured correlation structure provided the best fit for the repeated measures data and was used in the final models. A random effect for herd was included in all models to account for the clustering of cows at the herd level. As the main predictor, study group (BDCT+ITS or SDCT+ITS) was forced into the models. Other variables considered for inclusion were previous lactation 305-d milk production, infection status at drying off according to gold standard bacteriological culture, length of the dry period, parity at calving $(2,3$, or $>4)$, calving season, occurrence of postpartum disease (other than mastitis), DIM on the day of the milk test, herd size, housing type [freestall $(\mathrm{n}=11)$ vs. tiestall $(\mathrm{n}=5)]$, and region. Dry period was rescaled by subtracting $30 \mathrm{~d}$ from each observed value, which was the minimum possible value as dictated by the selection criteria. Previous lactation 305-d milk production was centered at the median value of $9,916 \mathrm{~kg}$ and scaled to reflect a change of $1,000 \mathrm{~kg}$. The variable for calving season was created using 3 mo intervals, such that winter was designated as December to February, spring as March to May, summer as June to August, and fall as September to November. Within the milk yield model, the effect of DIM was estimated with the addition of Wilmink's function, as illustrated by Schaeffer et al. (2000). To account for nonlinear trends for DIM in the $\operatorname{lnSCC}$ model, fractional polynomials were used and the best-fitting model was determined by the deviance difference. Unconditional associations between the various independent variables and the dependent variable of interest were assessed using simple linear regression, and variables with a $P$ value of 0.25 or less were offered as potential predictors in the multivariable models. With respect to model building, a backward stepwise procedure was used to select the best model and significance was declared at $P<0.05$. Once the variables to be included in the final model were determined, all first-order interactions with study group were examined and retained if significant. Additionally, an interaction between DIM and parity was also explored within each model. Dropped potentially confounding variables were reintroduced into the model and were retained if they changed the other model coefficients substantially. A random coefficient term for study group was evaluated at the herd level, but did not result in an improvement of the analysis of either milk yield or $\operatorname{lnSCC}$ based on a likelihood ratio test. The herd-level contextual effect of study group was assessed by the inclusion of an additional variable, representing the proportion of Petrifilm-positive cows for a particular herd, but was nonsignificant in both the milk yield and lnSCC models. The assumptions of the final models were assessed through examination of the residuals at the various levels.

\section{RESULTS}

\section{Descriptive Statistics}

In total, 729 cows were enrolled, of which 369 were assigned to BDCT+ITS and 360 were assigned to SDCT+ITS. The proportion of cows per herd eligible for inclusion ranged from $28.3(15 / 53)$ to $69.4 \%$ $(145 / 209)$, and the overall inclusion probability was $46 \%(729 / 1,584)$. Postenrollment exclusions and attrition resulted in the loss of 129 cows for the following reasons: death $(\mathrm{n}=15)$, sold $(\mathrm{n}=11)$, or culled ( $\mathrm{n}$ $=18$ ) before the first milk test, abortion $(\mathrm{n}=2)$, not pregnant $(\mathrm{n}=2)$, dry period $>90$ or $<30 \mathrm{~d}(\mathrm{n}=51)$, and contamination of all pre-drying off milk samples $(\mathrm{n}=30)$. No significant difference was noted between study groups with respect to postenrollment exclusion or attrition (BDCT+ITS: $62 / 369$ vs. SDCT+ITS: $67 / 360 ; P=0.52)$. Thus, 307 BDCT + ITS cows and 293 SDCT+ITS cows were available for analysis. The cowlevel prevalence of IMI at drying off in the SDCT+ITS group according to Petrifilm on-farm culture was $53.2 \%$ $(156 / 293)$. Therefore, at a Petrifilm treatment threshold of $\geq 50 \mathrm{cfu} / \mathrm{mL}, 46.8 \%(137 / 293)$ of the cows were classified as uninfected and did not receive a long-acting intramammary antimicrobial at drying off. Descriptive statistics for the cows included in the final analysis can be found in Table 1. Despite random allocation into treatment groups, the prevalence of IMI at drying off as determined by standard bacteriological culture was higher in cows assigned to SDCT+ITS than that observed in cows assigned to BDCT+ITS $(P=0.005)$. The prevalence of IMI postcalving was not different between the study groups $(P=0.72)$. As part of the clinical trial, clinical mastitis cases occurring in participating cows in the first $120 \mathrm{~d}$ of the next lactation were sampled and no significant difference we observed between the study groups (for details see Cameron et al., 2014).

\section{Test-Day Milk Production}

The results of the final repeated measures linear mixed model for milk production are presented in Table 2. When controlling for the other independent variables included in the model, test-day milk production was not different between cows receiving BDCT+ITS and cows selectively treated based on Petrifilm results [least 
Table 1. Descriptive statistics for cows enrolled in a randomized clinical trial to evaluate the use of a Petrifilmbased on-farm culture system in a selective dry cow therapy program ${ }^{1}$

\begin{tabular}{|c|c|c|}
\hline Item & $\begin{array}{c}\text { BDCT+ITS } \\
(\mathrm{n}=307)\end{array}$ & $\begin{array}{c}\text { SDCT+ITS } \\
(\mathrm{n}=293)\end{array}$ \\
\hline $\mathrm{SCC}^{2}\left(\mathrm{x} 10^{3} / \mathrm{mL}\right)$ & $36(12,228)$ & $39(14,268)$ \\
\hline $24-\mathrm{h}$ milk production ${ }^{3}(\mathrm{~kg})$ & $41.4(8.2)$ & $40.8(8.2)$ \\
\hline Previous 305-d milk production ${ }^{4}(\mathrm{~kg})$ & $9,995(1,865)$ & $9,903(1,766)$ \\
\hline Length of the dry period ${ }^{4}(d)$ & $59(11)$ & $60(12)$ \\
\hline \multicolumn{3}{|l|}{ Parity at calving } \\
\hline 2 & 149 & 142 \\
\hline 3 & 78 & 64 \\
\hline $4+$ & 80 & 87 \\
\hline \multicolumn{3}{|l|}{ Calving season } \\
\hline Spring (March-May) & 58 & 57 \\
\hline Summer (June-August) & 79 & 76 \\
\hline Fall (September-November) & 94 & 93 \\
\hline Winter (December-February) & 76 & 67 \\
\hline Prevalence of postpartum disease ${ }^{5}$ & 5.9 & 5.2 \\
\hline Cows with IMI $^{6}$ at drying off (\%) & $33.2^{* *}$ & $44.4^{* *}$ \\
\hline Cows with IMI ${ }^{6}$ after calving (\%) & 38.7 & 40.1 \\
\hline
\end{tabular}

${ }^{1} \mathrm{BDCT}+\mathrm{ITS}=$ blanket dry cow therapy (DCT) plus internal teat sealant (ITS); SDCT+ITS = selective DCT based on Petrifilm (3M Canada, London, Ontario) on-farm culture results with ITS alone (Petrifilm negative), or DCT and ITS (Petrifilm positive).

${ }^{2}$ Median (10th and 90th percentile) SCC in the first $180 \mathrm{~d}$ of the subsequent lactation.

${ }^{3}$ Mean (SD) 24-h milk production in the first $180 \mathrm{~d}$ of the subsequent lactation.

${ }^{4}$ Mean (SD).

${ }^{5}$ Excluding clinical mastitis. Occurring within the first $18 \mathrm{~d}$ of lactation.

${ }^{6}$ Definition of IMI $=$ all pathogens except CNS $\geq 100 \mathrm{cfu}$ per $1.0 \mathrm{~mL}$ of milk; CNS $\geq 200 \mathrm{cfu}$ per $1.0 \mathrm{~mL}$ of milk (Dohoo et al., 2011).

** $P<0.01$.

squares means: BDCT+ITS $=39.3 \mathrm{~kg}(95 \%$ CI: 37.9, $40.8)$ vs. $\mathrm{SDCT}+\mathrm{ITS}=39.0 \mathrm{~kg}(95 \%$ CI: 37.6, 40.5); $P=0.43]$. The $95 \%$ confidence interval for the coefficient of study group was -1.01 to $0.43 \mathrm{~kg}$, therefore the largest treatment effect supported by the data ranged from $1.01 \mathrm{~kg}$ favoring the $\mathrm{BDCT}+\mathrm{ITS}$ group to $0.43 \mathrm{~kg}$ favoring the SDCT+ITS group. For every $1,000-\mathrm{kg}$ increase in the previous lactation $305-\mathrm{d}$ milk yield, average daily milk production increased by 2.04 $\mathrm{kg}(P<0.001)$. According to simple linear regression, higher milk production was observed for cows in their third or greater lactation than for cows in their second lactation. However, in the multivariable model, which adjusted for previous lactation production, cows in their third lactation $(P<0.001)$ and fourth or greater lactation $(P<0.001)$ produced less than cows in their second lactation. As production changes with lactation number, the best comparison between parities would therefore be at each parity's mean production level during the previous lactation. For example, a third parity cow achieving 10,711 kg in her second lactation (third parity group's average production in lactation 2) produced $1.84 \mathrm{~kg}$ more per test day than a second parity cow that achieved $8,868 \mathrm{~kg}$ in her first lactation (second parity group's average production in lactation one). Calving season was also a significant predictor of milk production $(P<0.001)$, with cows calving in the summer having lower production than cows calving during any other season. Milk production increased with increasing duration of the dry period beyond 30 d (to a maximum of $90 \mathrm{~d}$ as dictated by the inclusion criteria; $P=0.007$ ), and the occurrence of postpartum disease other than mastitis reduced milk yield by an average of $2.64 \mathrm{~kg}$ per day $(P=0.001)$. Stage of lactation, modeled by the variables DIM and Wilmink's function, followed what is considered a standard lactation curve with an initial rise to a peak around $50 \mathrm{~d}$, followed by a gradual decline over time (Macciotta et al., 2005). Illustrated in Figure 1 is the estimated test-day 24-h milk yield by DIM for the 2 study groups.

\section{Test-Day SCC}

The results of the final repeated measures linear mixed model for $\operatorname{lnSCC}$ are presented in Table 3. After adjusting for other independent variables included in the final model, no significant difference in test-day $\operatorname{lnSCC}$ was observed between cows receiving BDCT + ITS and cows selectively treated at drying off based on Petrifilm results [least squares means: BDCT + ITS $=3.95(95 \%$ CI: $3.79,4.10)$ vs. SDCT+ITS $=3.97(95 \%$ CI: 3.81 , 4.12); $P=0.82$. The $95 \%$ confidence interval for the coefficient of study group was -0.13 to 0.16 (equivalent to -878 to 1,174 cells $/ \mathrm{mL}$ ); therefore, the largest treat- 
Table 2. Final multilevel model evaluating the effect of Petrifilm-based selective dry cow therapy on 24-h milk production $(\mathrm{kg})$ in the first $180 \mathrm{~d}$ of the subsequent lactation

\begin{tabular}{|c|c|c|c|c|}
\hline Variable & Coefficient & SE & $P$-value & $\begin{array}{l}\text { Overall } \\
P \text {-value }\end{array}$ \\
\hline \multicolumn{5}{|l|}{ Study group ${ }^{1}$} \\
\hline $\mathrm{BDCT}+\mathrm{ITS}$ & Reference & & & \\
\hline $\mathrm{SDCT}+\mathrm{ITS}$ & -0.29 & 0.37 & & 0.43 \\
\hline Length of the dry period ${ }^{2}$ & 0.050 & 0.018 & & 0.007 \\
\hline \multicolumn{5}{|l|}{ Calving season } \\
\hline Summer (Jun - Aug) & Reference & & & $<0.001$ \\
\hline Fall (Sep - Nov) & 1.12 & 0.50 & 0.024 & \\
\hline Winter (Dec - Feb) & 2.61 & 0.53 & $<0.001$ & \\
\hline Spring (Mar - May) & 2.05 & 0.57 & $<0.001$ & \\
\hline DIM & -0.088 & 0.0028 & & $<0.001$ \\
\hline WDIM $^{3}$ & -21.49 & 0.89 & & $<0.001$ \\
\hline \multicolumn{5}{|l|}{ Parity } \\
\hline 2nd lactation & Reference & & & $<0.001$ \\
\hline 3rd lactation & -1.93 & 0.53 & $<0.001$ & \\
\hline$\geq 4$ th lactation & -3.58 & 0.55 & $<0.001$ & \\
\hline Previous 305-d milk yield ${ }^{4}$ & 2.04 & 0.13 & & $<0.001$ \\
\hline Postpartum disease ${ }^{5}$ & -2.64 & 0.82 & & 0.001 \\
\hline Intercept & 49.66 & 0.99 & & \\
\hline \multicolumn{5}{|l|}{ Variance estimate } \\
\hline Herd-level variance & 4.87 & 2.18 & & \\
\hline Test-day variance $^{6}$ & $28.63-53.25$ & & & \\
\hline \multicolumn{5}{|c|}{$\begin{array}{l}{ }^{1} \text { BDCT }+ \text { ITS }=\text { blanket dry cow therapy }(\text { BDCT) plus internal teat sealant }(\text { ITS); SDCT }+ \text { ITS }=\text { selecti } \\
\text { cow therapy (SDCT) based on Petrifilm (3M Canada, London, Ontario) on-farm culture results with ITS } \\
\text { (Petrifilm negative), or dry cow therapy and ITS (Petrifilm positive). } \\
{ }^{2} \text { Minus } 30 \mathrm{~d} \text {. } \\
{ }^{3} \text { WDIM }=\text { Wilmink's function }=\mathrm{e}^{\text {DIM }(-0.05)} \text {. } \\
{ }^{4} \text { Centered at } 9,916 \mathrm{~kg} \text { and scaled to reflect a } 1,000-\mathrm{kg} \text { change. }\end{array}$} \\
\hline
\end{tabular}

ment effect supported by the data was decrease in SCC of 878 cells $/ \mathrm{mL}$ to an increase in SCC of 1,174 cells/ $\mathrm{mL}$ for SDCT+ITS compared with BDCT+ITS. Parity was significantly associated with $\operatorname{lnSCC}$, with cows in their third lactation $(P=0.029)$ and fourth or greater lactation $(P<0.001)$ having a higher average $\operatorname{lnSCC}$ than cows in their second lactation. Cows with an IMI at drying off according to standard bacteriological culture had a higher test-day $\operatorname{lnSCC}$ during the first 180 $\mathrm{d}$ of the next lactation than cows uninfected at drying off $(P=0.016)$. Fractional polynomials suggested that DIM was best modeled using the power terms 0.5 and -0.5. Illustrated in Figure 2 is the estimated test-day SCC by DIM for the 2 study groups. A similar pattern was apparent between groups with a rapid decrease in SCC from calving to approximately 50 DIM, followed by a gradual increase over time.

\section{DISCUSSION}

\section{Test-Day Milk Production}

It is estimated that IMI present at calving, either as a result of failure to eliminate existing infections or acquisition of new infections, can reduce lactation milk yields by $5 \%$ (Hogeveen, 2003; Berry et al., 2004). Thus, minimizing the prevalence of IMI postpartum is important for achieving optimum milk production. The successful outcome of an SDCT program depends on the accurate diagnosis of infection status at drying off so that DCT is applied appropriately and judiciously for the purpose of eliminating existing IMI. Furthermore, as prior studies have demonstrated that untreated quarters are at higher risk for the development of new IMI over the dry period, it is also important that a method to protect quarters against new IMI be in place, especially for cows not infused with DCT (Rindsig et al., 1978; Berry and Hillerton, 2002). According to the present study, when low-SCC cows were selectively treated with DCT at drying off based on results obtained using the Petrifilm on-farm culture system, no effect on milk production was noted in the subsequent lactation when compared with cows receiving BDCT. The Petrifilm on-farm culture system provided sensitive results, thus enabling the accurate diagnosis of cows with an IMI at the end of lactation (Cameron et al., 2013). Moreover, ITS were used in all cows, thus ensuring some measure of prophylaxis against IMI for all quarters. Whereas ITS have been evaluated for use in SDCT in terms of infection status at calving and clinical mastitis in 
Table 3. Final multilevel model evaluating the effect of Petrifilm-based selective dry cow therapy on natural $\log$ SCC $(\operatorname{lnSCC})$ in the first $180 \mathrm{~d}$ of the subsequent lactation

\begin{tabular}{|c|c|c|c|c|}
\hline Variable & Coefficient & $\mathrm{SE}$ & $P$-value & $\begin{array}{l}\text { Overall } \\
P \text {-value }\end{array}$ \\
\hline \multicolumn{5}{|l|}{ Study group ${ }^{1}$} \\
\hline BDCT+ITS & Reference & & & \\
\hline SDCT+ITS & 0.017 & 0.075 & & 0.82 \\
\hline \multicolumn{5}{|l|}{ Parity } \\
\hline 2nd lactation & Reference & & & $<0.001$ \\
\hline 3rd lactation & 0.21 & 0.094 & 0.029 & \\
\hline$\geq 4$ th lactation & 0.32 & 0.090 & $<0.001$ & \\
\hline$\overline{\mathrm{DI}} \mathrm{M}^{(-0.5) 2}$ & 6.94 & 0.60 & & $<0.001$ \\
\hline $\operatorname{DIM}^{(0.5) 2}$ & 0.14 & 0.014 & & $<0.001$ \\
\hline IMI status at drying off ${ }^{3}$ & 0.19 & 0.079 & & 0.016 \\
\hline Intercept & 1.55 & 0.22 & & \\
\hline \multicolumn{5}{|l|}{ Variance estimate } \\
\hline Herd-level variance & 0.042 & 0.028 & & \\
\hline Test-day variance ${ }^{4}$ & $1.25-1.61$ & & & \\
\hline \multicolumn{5}{|c|}{$\begin{array}{l}{ }_{1}^{1} \text { BDCT }+ \text { ITS }=\text { blanket dry cow therapy (BDCT) plus internal teat sealant (ITS); SDCT }+ \text { ITS }=\text { selective dry } \\
\text { cow therapy (SDCT) based on Petrifilm (3M Canada, London, Ontario) on-farm culture results with ITS alone } \\
\text { (Petrifilm negative), or dry cow therapy and ITS (Petrifilm positive). }\end{array}$} \\
\hline
\end{tabular}

the subsequent lactation, no other studies to date have published data pertaining to the effect of SDCT and ITS on milk production. In a decision tree analysis evaluating dry cow protocols by Berry et al. (2004), comparisons were made between cows receiving DCT and negative controls, as well as cows receiving ITS

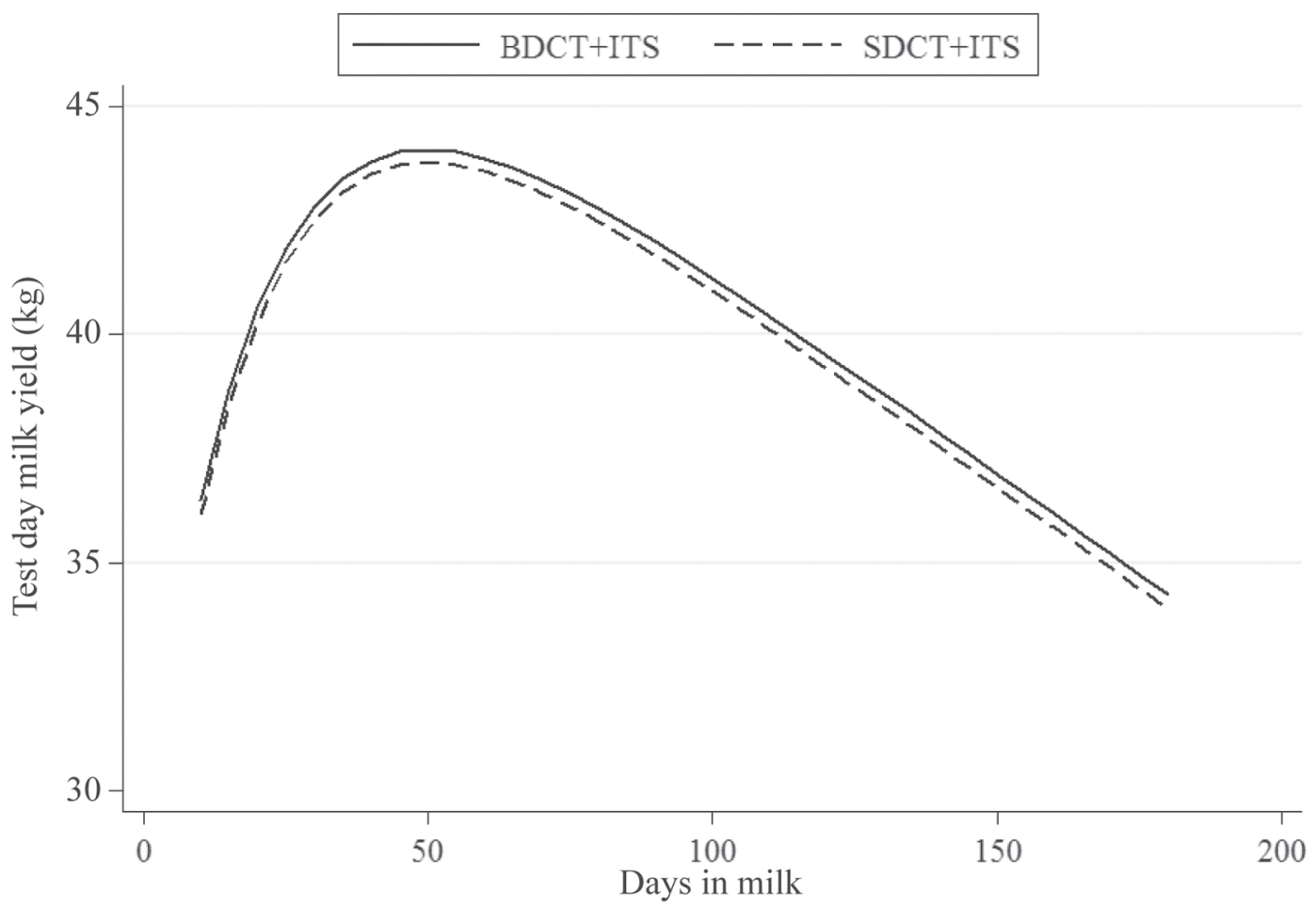

Figure 1. Graph of test-day milk production (least squares means) by DIM for cows receiving blanket dry cow antimicrobial therapy plus internal teat sealant (BDCT+ITS) and cows selectively treated at drying off based on Petrifilm (3M Canada, London, Ontario) on-farm culture results (SDCT+ITS). Presented estimates are for cows in their second lactation, with previous lactation milk production set at 8,868 kg and prevalence of postpartum disease set at the overall observed value of $5.3 \%$. 


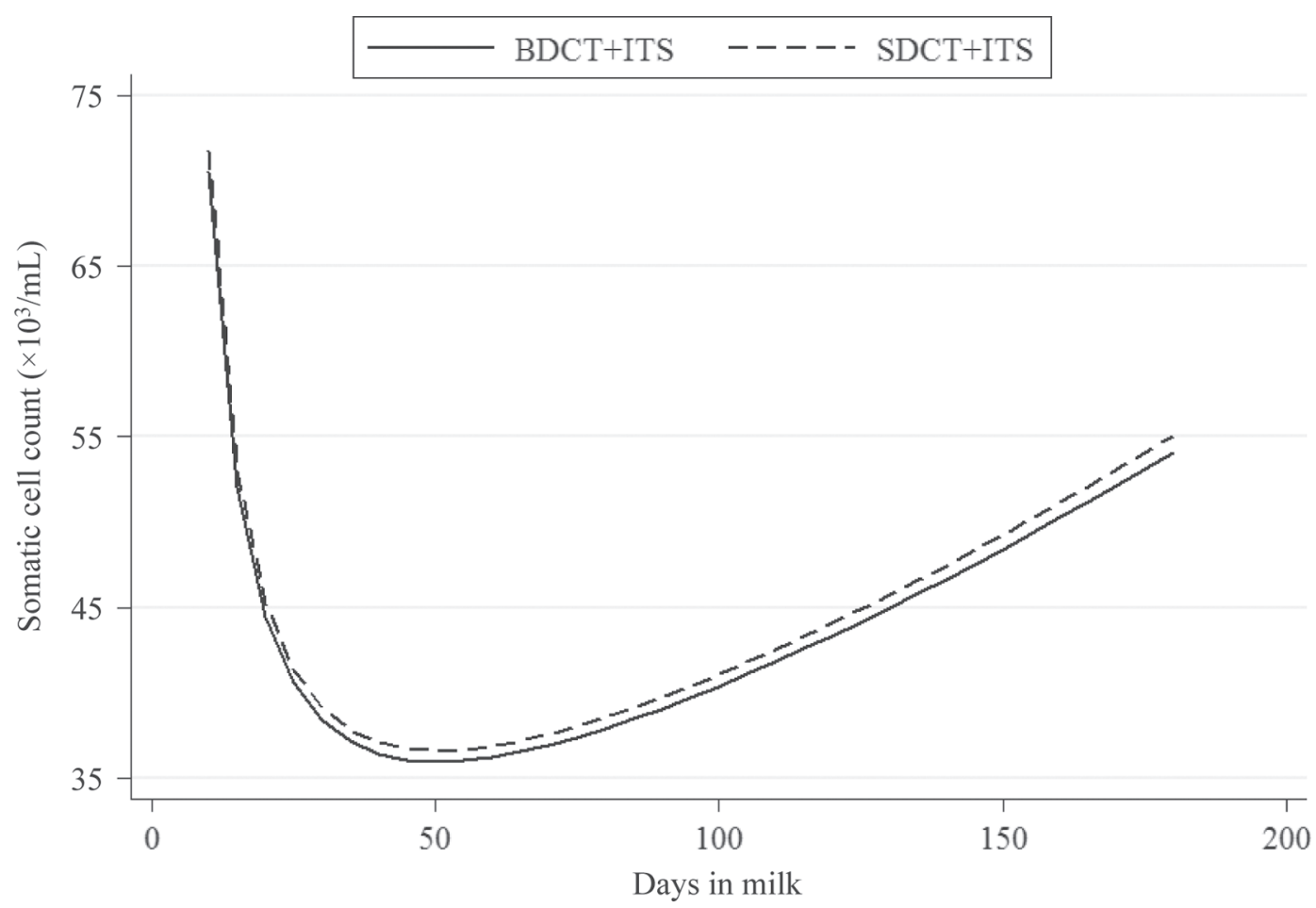

Figure 2. Graph of SCC (least squares means) by DIM for cows receiving blanket dry cow antimicrobial therapy plus internal teat sealant (BDCT+ITS) and cows selectively treated at drying off based on Petrifilm (3M Canada, London, Ontario) on-farm culture results (SDCT+ITS). Presented estimates are for cows in their second lactation with prevalence of IMI at drying off set at the overall observed value of $38.5 \%$.

and negative controls, and it was determined that DCT had a positive effect on milk yield but there was no effect of ITS. The data originated from 2 separate clinical trials involving cows that were either uninfected or infected with CNS or Corynebacterium spp. at drying off, and assignment to treatment groups was based on randomization. In previous works evaluating the effect of DCT on milk production, when random assignment to treatment groups was used, DCT displayed a significant positive effect on production when compared with a negative control (Osterås and Sandvik, 1996; Berry et al., 1997, 2004). However, when selection procedures were put in place, DCT lost its production-related effect. According to Rajala-Schultz et al. (2011), there was no effect of DCT on milk production when BDCT was compared with no treatment in cows with a low SCC and no clinical mastitis before drying off. This is in agreement with the current study, further demonstrating the importance of the selection protocol for SDCT.

With regard to the effect of parity on milk production, the data indicated that cows entering their second lactation produced more milk than cows beginning their third or greater lactation. However, because the final model also controlled for previous lactation milk production, this finding actually reflected the greater capacity of second parity cows to increase their milk production over the previous lactation than higher parity cows. This, coupled with the significant positive association between previous lactation production and current production, is in agreement with Rajala-Schultz et al. (2011). Season of calving as a predictor of milk production has also been explored elsewhere, and the results of this trial are in accord with previous research (Wilmink, 1987; Rajala-Schultz et al., 2011). Finally, the occurrence of postpartum disease has been shown to be a risk factor for decreased milk production (Wilson et al., 2004), therefore it was not surprising that cows experiencing one of the recorded disease events sometime between calving and 18 DIM had lower milk production than that observed in cows that remained healthy. Whereas mastitis events were recorded, mastitis was not included in the list of postpartum diseases. Mastitis in the postpartum period was considered an intervening variable between study group and milk yield, and inclusion of mastitis would have resulted in a biased measure of the effect of study group on milk production (Dohoo et al., 2009).

\section{Test-Day SCC}

In the current study, the selective antimicrobial treatment of cows at the end of lactation based on Petrifilm culture results did not affect the SCC in the following 
lactation when compared with cows that received total antimicrobial therapy at drying off. In earlier studies comparing $\mathrm{BDCT}$ to a negative control group, cows receiving DCT had a lower SCC in the subsequent lactation than cows left untreated over the dry period (McNab and Meek, 1991; Osterås and Sandvik, 1996; McDougall, 2010; Rajala-Schultz et al., 2011). This illustrates the importance of providing some form of protection, such as ITS, for quarters of cows that do not receive DCT. Comparisons of the effect of ITS alone versus DCT on SCC are infrequent in the literature. In a split-udder trial involving cows without an IMI at drying off, when the SCC at 1 to 8 DIM was compared between quarters receiving ITS and quarters infused with DCT, the proportion of quarters with an SCC $>200,000$ was $37 \%$ in the ITS group and $36 \%$ in the DCT group (Sanford et al., 2006). In an observational study by Green et al. (2008) examining dry period risk factors associated with high SCC in early lactation, it was concluded that DCT and ITS had the same effect on SCC in early lactation when used in cows with a low SCC before drying off.

Regarding the other significant associations revealed in the final regression model, the findings are in agreement with previous research. Parity as a significant predictor of SCC has been reported elsewhere and is commonly attributed to increased risk of IMI and clinical mastitis (Laevens et al., 1997; Walsh et al., 2007; Pantoja et al., 2009). Cows with an IMI at drying off according to gold standard laboratory culture had a higher SCC in the subsequent lactation than cows uninfected at drying off. Previous IMI has been shown to be a risk factor for the development of new IMI (Zadoks et al., 2001; Green et al., 2002).

\section{CONCLUSIONS}

Although much research has examined the outcome of SDCT on IMI at calving and clinical mastitis in early lactation, investigations into milk production and milk quality outcomes are lacking. The use of a Petrifilmbased on-farm culture system to make targeted DCT treatment decisions on cows with a low SCC at the end of lactation did not affect milk production and SCC in the subsequent lactation as compared with BDCT. Overall, Petrifilm-based SDCT with the addition of an ITS enabled a reduction in the use of antimicrobials on low-BTSCC dairy farms without affecting the health and future milk production of the cow.

\section{ACKNOWLEDGMENTS}

This research was financed by Maritime Quality Milk, a research program of the Atlantic Veterinary
College of the University of Prince Edward Island and Novalait Inc. (Quebec, Canada). Additional funding was provided by the Prince Edward Island Department of Innovation and Advanced Learning (Charlottetown, PE, Canada). The authors thank François Dubois (Faculté de médecine vétérinaire, Université de Montréal, Saint-Hyacinthe, Québec, Canada), Theresa Andrews, Natasha Robinson, and Lloyd Dalziel (all of Atlantic Veterinary College, University of Prince Edward Island, Charlottetown, PE, Canada) for their technical assistance, the laboratory personnel from Maritime Quality Milk, and the participating dairy producers.

\section{REFERENCES}

Berry, E. A., and J. E. Hillerton. 2002. The effect of selective dry cow treatment on new intramammary infections. J. Dairy Sci. $85: 112-121$.

Berry, E. A., H. Hogeveen, and J. E. Hillerton. 2004. Decision tree analysis to evaluate dry cow strategies under UK conditions. J. Dairy Res. 71:409-418.

Berry, S. L., J. Maas, J. H. Kirk, J. P. Reynolds, I. A. Gardner, and A. Ahmadi. 1997. Effects of antimicrobial treatment at the end of lactation on milk yield, somatic cell count, and incidence of clinical mastitis during the subsequent lactation in a dairy herd with a low prevalence of contagious mastitis. J. Am. Vet. Med. Assoc. 211:207-211.

Cameron, M., G. P. Keefe, J. P. Roy, I. R. Dohoo, K. A. MacDonald, and S. L. McKenna. 2013. Evaluation of a 3M Petrifilm on-farm culture system for the detection of intramammary infection at the end of lactation. Prev. Vet. Med. 111:1-9.

Cameron, M., S. L. McKenna, K. A. Macdonald, I. R. Dohoo, J. P. Roy, and G. P. Keefe. 2014. Evaluation of selective dry cow treatment following on-farm culture: Risk of postcalving intramammary infection and clinical mastitis in the subsequent lactation. J. Dairy Sci. 97:270-284

Dingwell, R. T., D. F. Kelton, and K. E. Leslie. 2003. Management of the dry cow in control of peripartum disease and mastitis. Vet. Clin. North Am. Food Anim. Pract. 19:235-265.

Dohoo, I. R., S. W. Martin, and H. Stryhn. 2009. Veterinary Epidemiologic Research. 2nd ed. VER Inc., Charlottetown, PEI, Canada.

Dohoo, I. R., J. Smith, S. Andersen, D. F. Kelton, and S. Godden. 2011. Diagnosing intramammary infections: Evaluation of definitions based on a single milk sample. J. Dairy Sci. 94:250-261.

Dufour, S., I. R. Dohoo, H. W. Barkema, L. Descoteaux, T. J. Devries, K. K. Reyher, J. P. Roy, and D. T. Scholl. 2012. Manageable risk factors associated with the lactational incidence, elimination, and prevalence of Staphylococcus aureus intramammary infections in dairy cows. J. Dairy Sci. 95:1283-1300.

Green, M. J., A. J. Bradley, G. F. Medley, and W. J. Browne. 2008. Cow, farm, and herd management factors in the dry period associated with raised somatic cell counts in early lactation. J. Dairy Sci. 91:1403-1415.

Green, M. J., L. E. Green, G. F. Medley, Y. H. Schukken, and A. J. Bradley. 2002. Influence of dry period bacterial intramammary infection on clinical mastitis in dairy cows. J. Dairy Sci. 85:25892599.

Halasa, T., M. Nielen, A. C. Whist, and O. Østerås. 2009. Metaanalysis of dry cow management for dairy cattle. Part 2. Cure of existing intramammary infections. J. Dairy Sci. 92:3150-3157.

Hand, K. J., A. Godkin, and D. F. Kelton. 2012. Milk production and somatic cell counts: A cow-level analysis. J. Dairy Sci. 95:13581362 .

Hogeveen, H. 2003. Economic aspects of dry cow therapy. Pages 42 49 in Proceedings of the National Mastitis Council 42nd Annual Meeting, Fort Worth, TX. National Mastitis Council, Verona, WI. 
Huxley, J. N., M. J. Green, L. E. Green, and A. J. Bradley. 2002. Evaluation of the efficacy of an internal teat sealer during the dry period. J. Dairy Sci. 85:551-561.

Laevens, H., H. Deluyker, Y. H. Schukken, L. De Meulemeester, R. Vandermeersch, E. De Muelenaere, and A. De Kruif. 1997. Influence of parity and stage of lactation on the somatic cell count in bacteriologically negative dairy cows. J. Dairy Sci. 80:3219-3226.

Macciotta, N. P., D. Vicario, and A. Cappio-Borlino. 2005. Detection of different shapes of lactation curve for milk yield in dairy cattle by empirical mathematical models. J. Dairy Sci. 88:1178-1191.

McDougall, S. 2010. A randomised, non-inferiority trial of a new cephalonium dry-cow therapy. N. Z. Vet. J. 58:45-58.

McNab, W. B., and A. H. Meek. 1991. A benefit cost analysis of dry-cow mastitis therapy in Ontario dairy herds. Can. Vet. J. $32: 347-353$.

National Mastitis Council. 1999. Laboratory Handbook on Bovine Mastitis Revised Edition. National Mastitis Council Inc., Madison, WI.

Osterås, O., and L. Sandvik. 1996. Effects of selective dry-cow therapy on culling rate, clinical mastitis, milk yield and cow somatic cell count. A randomized clinical field study in cows. Zentralbl. Veterinarmed. B. 43:555-575.

Pantoja, J. C., C. Hulland, and P. L. Ruegg. 2009. Somatic cell count status across the dry period as a risk factor for the development of clinical mastitis in the subsequent lactation. J. Dairy Sci. 92:139 148.

Rajala-Schultz, P. J., A. H. Torres, and F. J. Degraves. 2011. Milk yield and somatic cell count during the following lactation after selective treatment of cows at dry-off. J. Dairy Res. 78:489-499.

Reyher, K. K., S. Dufour, H. W. Barkema, L. Des Coteaux, T. J. Devries, I. R. Dohoo, G. P. Keefe, J. P. Roy, and D. T. Scholl. 2011. The National Cohort of Dairy Farms-A data collection platform for mastitis research in Canada. J. Dairy Sci. 94:1616-1626.

Rindsig, R. B., R. G. Rodewald, A. R. Smith, and S. L. Spahr. 1978 Complete versus selective dry cow therapy for mastitis control. J. Dairy Sci. 61:1483-1497.

Robert, A., P. Roussel, N. Bareille, D. Ribaud, F. Serieys, V. Heuchel, and H. Seegers. 2008. Risk factors for new intramammary infections during the dry period in untreated dairy cows from herds using selective dry cow therapy. Animal 2:247-254.

Roy, J. P., D. Du Tremblay, L. Descoteaux, S. Messier, D. Scholl, and E. Bouchard. 2009. Evaluation of the California mastitis test as a precalving treatment selection tool for Holstein heifers. Vet. Microbiol. 134:136-142.
Sanford, C. J., G. P. Keefe, I. R. Dohoo, K. E. Leslie, R. T. Dingwell, L. DesCoteaux, and H. W. Barkema. 2006. Efficacy of using an internal teat sealer to prevent new intramammary infections in nonlactating dairy cattle. J. Am. Vet. Med. Assoc. 228:1565-1573.

Schaeffer, L. R., J. Jamrozik, G. J. Kistemaker, and B. J. Van Doormaal. 2000. Experience with a test-day model. J. Dairy Sci. $83: 1135-1144$

Seegers, H., C. Fourichon, and F. Beaudeau. 2003. Production effects related to mastitis and mastitis economics in dairy cattle herds. Vet. Res. 34:475-491.

Smith, K. L., D. A. Todhunter, and P. S. Schoenberger. 1985. Environmental pathogens and intramammary infection during the dry period. J. Dairy Sci. 68:402-417.

Torres, A. H., P. J. Rajala-Schultz, F. J. Degraves, and K. H. Hoblet. 2008. Using dairy herd improvement records and clinical mastitis history to identify subclinical mastitis infections at dry-off. J. Dairy Res. 75:240-247.

USDA. 2008. Dairy 2007. Part III: Reference of Dairy Cattle Health and Management Practices in the United States, 2007. USDAAnimal and Plant Health Inspection Service-Veterinary Service, Center for Epidemiology and Animal Health, National Animal Health Monitoring System, Fort Collins, CO.

Walsh, S., F. Buckley, D. P. Berry, M. Rath, K. Pierce, N. Byrne, and P. Dillon. 2007. Effects of breed, feeding system, and parity on udder health and milking characteristics. J. Dairy Sci. 90:5767-5779.

Wilmink, J. B. M. 1987. Adjustment of test-day milk, fat and protein yield for age, season and stage of lactation. Livest. Prod. Sci. 16:335-348.

Wilson, D. J., R. N. González, J. Hertl, H. F. Schulte, G. J. Bennett, Y. H. Schukken, and Y. T. Gröhn. 2004. Effect of clinical mastitis on the lactation curve: A mixed model estimation using daily milk weights. J. Dairy Sci. 87:2073-2084.

Woolford, M. W., J. H. Williamson, A. M. Day, and P. J. Copeman. 1998. The prophylactic effect of a teat sealer on bovine mastitis during the dry period and the following lactation. N. Z. Vet. J. 46:12-19.

Zadoks, R. N., H. G. Allore, H. W. Barkema, O. C. Sampimon, G. J. Wellenberg, Y. T. Grohn, and Y. H. Schukken. 2001. Cow- and quarter-level risk factors for Streptococcus uberis and Staphylococcus aureus mastitis. J. Dairy Sci. 84:2649-2663. 